\title{
Urdu Translation and Validation of Trust in Close Relationship Scale
}

\author{
Hira Jahangier *, Dr. Syeda Shahida Batool **
}

\begin{abstract}
The current study aimed to translate Trust in Close Relationship Scale (Holmes \& Rempel, 1989) in Urdu for married couples in Pakistan and to establish its psychometric properties. The forward and backward translation method (Brislin, 1970,1976) was used for the translation of scale. After determining the cross language validation of scale, in order to confirm the factor structure of the scale, confirmatory factor analysis (CFA) was run. The participants of study comprised of 250 married couples with the age ranging from 22 to 70 years $(M=39.7, S D=10.1)$. Both husbands and wives participated in the study and they had been living together for at least two years. The results of CFA supported the original threefactor structure of the scale (viz., Avoidance, Benevolence, and Retaliation) by providing a good model fit to the data with values of $X^{2}=229.61$ ( $\left.d f=110, p<.001\right), C F I=.91, G F I=.91$, and RMSEA $=.06$. Cronbach's alpha reliability coefficient of the scale was $\alpha=.87$. The convergent validity of the scale was established on a sample of 100 participants by finding its correlation with Trust Scale $(r=.72, p<.001)$. The results indicate that trust scale is a promising assessment tool having good reliability and validity.
\end{abstract}

Keywords: Trust, married couples, cross language validation, confirmatory factor analysis, convergent validity.

This Article can be cited as:

Jahangier H \& Batool S S (2020). Urdu Translation and Validation of Trust in Close Relationship Scale, Journal of Arts and Social Sciences. VII (2), 173-184.

\footnotetext{
* Hira Jahangier, PhD scholar, Department of Psychology, Government College University Lahore

** Correspondence concerning this article should be addressed to Prof. Dr. Syeda Shahida Batool, PhD Department of Psychology, Government College University Lahore, shahidaphd@yahoo.com
} 


\section{Introduction}

Individuals' trust or distrust depends on their previous life experiences, prior relationships and expectations from others. The level of trust in a given relationship largely depends on the attributions of current relationships (Holmes \& Rempel, 1989).

Dobing (1993) defined trust as composite of person's intention regarding his/her willingness to depend, beliefs regrading trust other people and context based trusting behavior. Trust is a product of spouses' intentions, beliefs and behavior to depend and their reliance on each other.

Similarly, William and Mark (2008) state trust as a salient determinant for indicating the level of marital adjustment and satisfaction among partners. According to Fatima and Ajmal (2012), trust is important factor for living a peaceful life for both partners because it gives you a sense of belongingness, autonomy and independence whereas lacking trust results in miserable life for couples, harming each other and lowers their marital satisfaction/quality.

According to Heller (2000), believing or trusting means that a person will do what you expect from them. Trust is a salient predictor in interpersonal relationship (Cottrell et al., 2007; Rotter, 1980).

Trust in marital couples is a powerful predictor of marital relationship and outcomes including stress, satisfaction, stability and continuity (Simpson, 1990). Trust in marital relationship is defined as the degree to which a spouse believes that his/her partner is fulfilling the required needs and assists in attainting goals. It comprises two important factors including dependability: getting support while facing problem and faith: confidence that s/he is with me (Simpson, 2007a).

Quality of marital life depends on marital satisfaction and couples' adjustments to their marriage (Shapiro et al., 2000). Karimi et al. (2019) extracted major factors that impact quality and stability of marriage including trust, love and attachment, communication and intimacy. Gondal et al. (2018) studied the relationship between Machiavellian personality trait, trust and marital satisfaction. The results of study indicated that having trust on each other results in high satisfaction and low Machiavellianism.

Studies have shown that the foundation of marital relationship is based on spousal trust that give sense of security and confidence to spouses (Gottman \& Sliver, 2016). Both spouses have certain expectations from each other and the major is the mutual trust (McNulty et al., 1981).

Researchers, and family and marital counselors/ therapists are focusing on the role of trust in marital relationship and marital outcomes (Gottman, 1999, 2002, 2011, 2015; Gottman \& Levenson, 2002). People who score lower on trust have poor satisfaction in marriage (Kelley \& Burgoon, 1991). Researchers proclaim that trust involves behavioral, emotional and cognitive dimensions (Lahno, 2004; McAllister, 1995) therefore, different research tools of trust are available focusing on different aspects but the most common factors are beliefs about honesty and trustworthiness of others, and factors of trusting others in these scales were developed by (Gottman, 2012; Yamagishi \& Yamagishi, 1994).

Very few instruments are available that primarily measure marital trust. Researchers in Pakistan have used some of the generic scales for example; The Trust in Close Relationship Scale by Rempel et al. (1985) was used by Atta et al. (2013) and Rao and Tariq (2015) to measure the relationship of trust and marital satisfaction. Similarly, Perceived Relationship Quality Scale developed by Fletcher, Simpson and Thomas (2000) was used by Makhdoom and Malik (2019) to measure the role of trust in rewarding and marital satisfaction in Muslim population especially, in Pakistan. Whereas, Trust in Interpersonal Relationships Scale by Larzelere and Huston (1980) was used by Franz (2012) to measure trust in marital relationship in different races (e.g., Asian, African, Hespanic and others). 
Measures to assess the level of trust among couples have never been indigenized in the context of Pakistan.Keeping in view the cultural limitations and comprehensiveness of existing scales, such as Perceived Relationship Quality Scale (Fletcher et al., 2000) and The General Trust Scale (Yamagishi, 1986), Rempel et al. (1985) gave a comprehensive measurei.e., Trust in Close Relationship Scale (TCRS). This scale was developed to measure the trust among people in close relations like married couples as well as expectations that they count on their partners to care and to be responsive for each other's needs. The scale comprises of seventeen items, having three subscales. All items response format is 7-point Likert type scale ranging from 1 as strongly disagree to 7 as strongly agree. Items on subscales includes Predictability (1, 7, 13, 15, and 17) Dependability (4, 5, 6, 8 and 14) and Faith (2, 3, 9, 10, 11, 12 and 16). Responses on all items of subscales represent a composite score or global index of spousal trust and higher scores indicate more trust on each other. The alpha reliabilities of total scale and subscales in previous researches reported in Campbell et al. (2010) are $\alpha=.74$ for women and $\alpha=.83$ for men.

Trust in Close Relationship Scale (TRCS) can be applicable on any population and has been used by authors in different countries like Franz (2012) used this scale in United States (Rowan University) to measure the impact of trust on attachment and interpersonal control in dating partners. Schneider (2011) used the same instrument in Amsterdam (Netherland) for assessing the role of trust in the health of dating couples.

Wong et al. (2015) studied the role of trust in marital quality and translated the revised version of scale in Chinese Language that named as Relationship Trust Scale by Holmes, Boon, and Adams (1990). This scale is designed to measure marital quality in both married and cohabiting couples.

Although the scale had been used in Pakistan for example by Atta et al. (2013) but no documented evidence was found on the translation and validation of TCRS and the author also confirmed via e-mail that he had not received any details from the researchers in Pakistan on Urdu translation and validation of the scale. As the scale was originally developed in English, so in order to use TRCS in Pakistan for research on trust in marital commitment, researchers need a valid and reliable Urdu version of the scale to measure mutual trust in married couples.

\subsection{Objectives of study}

1. To translate the Trust in Close Interpersonal Relationship Scale from English into Urdu language;

2. To determine the cross language validation of Urdu-version of Trust in Close Interpersonal Relationship Scale;

3. To confirm the factor structure of Urdu- version Trust in Close Interpersonal Relationship Scale;

4. To determine the convergent validity of Trust in Close Interpersonal Relationship Scale.

\section{Methodology}

The objectives of the present study were achieved in four phases. In Phase 1, the scale was translated; in Phase II, cross language validation was determined; in Phase III, confirmatory factor analysis (CFA) was run and reliability of the scale was established; and phase IV was designed to determine the convergent validity of the scale.

\subsection{Phase I: Translation of Trust in Close Relationship Scale}

The permission for using the scale after translation of the same in Urdu language was taken from the authors of TCRS scale (Rempel et al., 1985). The translation process was divided in three steps: 


\subsubsection{Forward Translation}

First of all, the scale was translated from original language (English) into Urdu as per standardized procedure for scale translation (Brislin, 1970, 1976). Four bilingual experts: one professor, two assistance professors and one PhD student from psychology department of GC University, Lahore were approached by the authors. All of them were proficient in both languages (source and target language), had understanding of both cultures and had previous experience in psychological assessment, test development, translation, construction and validation. The experts were requested to review technical equivalence of language in translated version of scale; such as grammar, tenses, length, appropriate abstraction's level and relation with social-cultural context. Following this process, four independent Urdu translated versions of Trust within Close Interpersonal Relationship scale were developed.

\subsubsection{Committee Evaluation of Translated Items}

Committee approach was used in order to get the best fitting translation items of scale by comparing the four independent forwarded translation versions as well as to assess the theoretical uniformity in items. This committee consisted of bilingual experts (equally proficient in use of English and Urdu): a professor, two assistant professors, and a lecturer from GC University Lahore. They were requested to critically analyze individual items of scale in the light of cultural context, grammar and wording by these experts who later selected best translated items for the scale that denoted the best meaning. Finally, forwarded translated version of the scale was retained with the consensus of experts.

\subsubsection{Backward translation}

In the third step, the final version of Urdu translated trust scale that comprised of all the best Urdu translated items as recommended by experts was translated back into English language independently by a bilingual expert. The purpose of backward translation was to ensure that the Urdu version of the scale had equivalence with the original scale.

\subsection{Phase II: Cross Language Validation}

In Phase II, Cross language validation of Urdu translated version of Trust in Close Relationship Scale was carried out. Correlation of Urdu version of the scale was calculated with original English version and Backward translated English version to assess the quality of Urdu scale and for determining its empirical equivalence with original English Scale.

Initially, in this phase, a try out study was conducted on twenty married individuals of age between 28 to 48 year $($ men $=10$, women $=10$ ) to check the comprehensibility, language, understanding and clarity of finalized items of Urdu translated version. The researcher asked the participants to inform any ambiguity if they had in any item of translated scale but no one reported any issue regarding clarity and comprehensibility in entire scale. So, it was decided to use this scale for the subsequent analyses.

The cross language validation of Urdu translated version of Trust in Close Relationship Scale was carried out afterward.

\subsubsection{Sample}

A sample of 30 married couples including both husbands and wives with the age range from 28 to 50 years $(M=35.1, S D=4.7)$ were selected for this study. All were married and had been living together for at least two years as married partners. Educational level of participants ranged between graduation and post-graduation levels and they belonged to different socioeconomic backgrounds. 


\subsubsection{Procedure}

For cross validation of Urdu translated scale, the sample was divided into two groups (30 participants in each group). The scale was administered in reverse order; group 1 received the order of original English version, Urdu version, and backward translated version. Whereas, group 2 was given backward translated version, Urdu version, and English version. It was done in order to control the carry over effect, to assess any discrepancy and ensuring the unbiased equivalence between Urdu and original English versions of the scale. Correlation analysis was run in order to assess the empirical evidence for the language equivalence of both versions.

Table 1. Inter-correlations between Three Versions of Trust in Close Relationship Scale $(N=60)$

\begin{tabular}{llll}
\hline Scale & 1 & 2 & 3 \\
\hline Trust-Original English version & - & $.87^{* *}$ & $.75^{* *}$ \\
Trust-Forward Urdu Translation & & - & $.76^{* *}$ \\
Trust-Backward English Translation & & & - \\
\hline
\end{tabular}

$* * p<.01$

Table 1 shows the correlations among three versions of the scale. All versions of the scales have significant positive correlations and values of correlation coefficients range from .75 to .86 . Overall results indicate that the content of Urdu version of TCRS is to the greater extent empirically equivalent to its English version.

\subsection{Phase III: Determining Psychometric Properties of Urdu Translation of TCRS}

The data were analyzed for determining the factorial validity and reliability of the scale by using AMOS 20 and SPSS software.

\subsubsection{Sample}

The participants of study comprised of 250 married couples with the age ranging from 22 to 70 years $(M=39.7, S D=10.1)$. Both husbands and wives participated in the study and they had been living together for at least two years. Data were collected from the couples separately in their preferred timeslots and places. The data were collected from couples living in District Lahore. Participants belonged to diverse socio-economic background (viz., low, middle, and high).

\subsubsection{Procedure}

A Convenient Purposive sampling was used to approach and collect the data from married Pakistani couples taken from the district Lahore. The first author of the study personally contacted the participants and briefed them about the purpose of study. The author provided instruction about Likert type response-format and completion of scale. It was ensured that they clearly understood the instructions of completing these measures and all the queries of participants were answered prior to attempting to get the questionnaire completed. Confidentially of information provided by the participants and data protection procedures were ensured. Initially 300 forms were distributed, out of which,250 forms completed by both married partners were finalized for subsequent analyses.

\subsection{Results}




\subsubsection{Confirmatory Factor Analysis}

To confirm the factor structure and measurement model of Trust within Close Interpersonal Relationship, a confirmatory factor analysis (CFA) was carried out. To explain the best model fit, various indices e.g. CFI, GFI and RMSEA and criteria were checked.

Table 2. Model Fit Indices $(N=250)$

\begin{tabular}{lllllllll}
\hline Indexes & $C M I N$ & $D f$ & CMIN/df & $P$ & $C F I$ & $R M S E A$ & $T L I$ & GFI \\
\hline Final Model & 229.61 & 110 & 2.08 & .000 & .91 & .06 & .90 & .91 \\
\hline
\end{tabular}

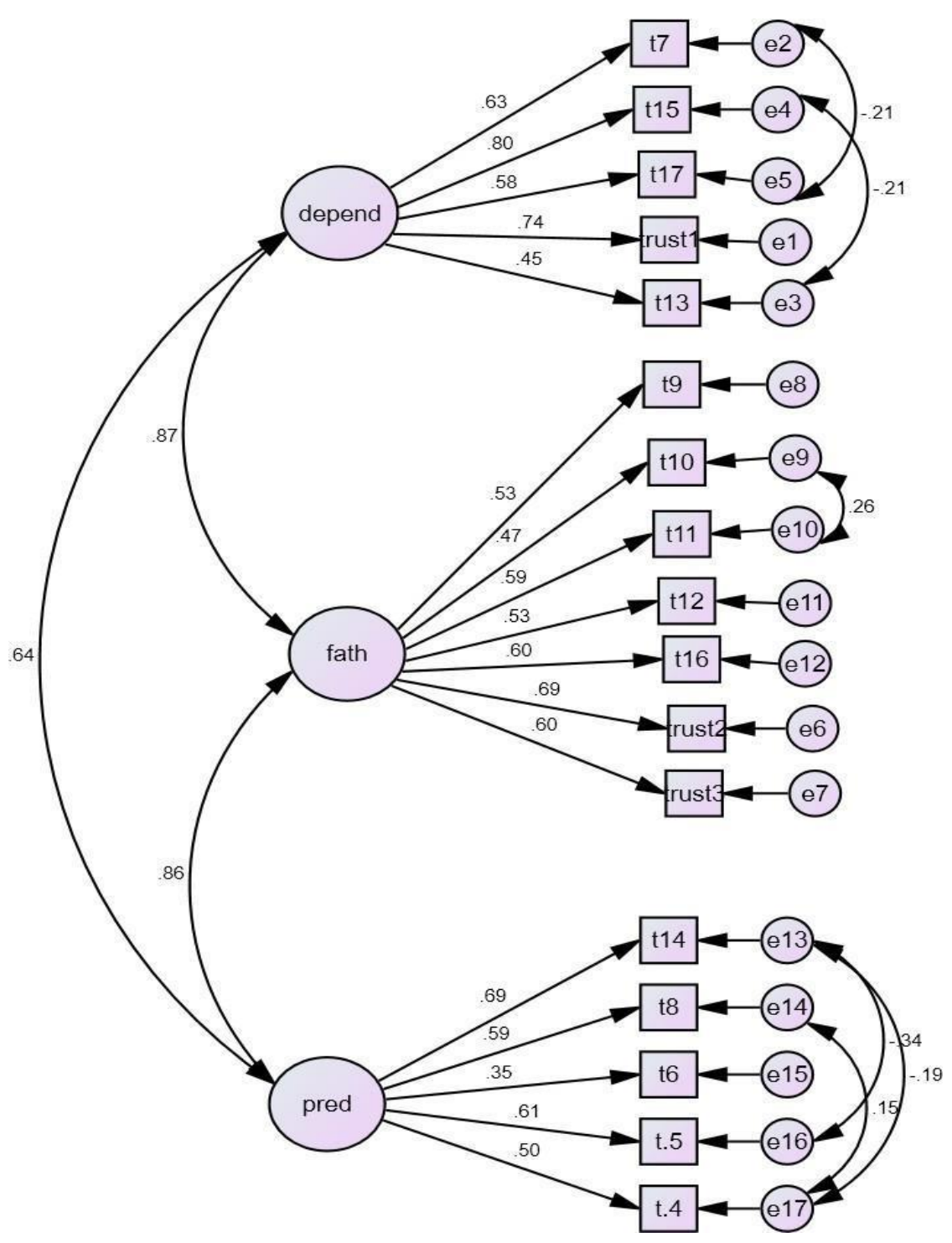

Figure 1. Model of Urdu Translated Trust in Close Relationship Scale 
Table 2 and Figure 1 show values of model fit indices and factors loadings for translated Trust within Close Interpersonal Relationship Scale. On the bases of best model fit indices, in initial criteria it was decided that no item had loading less than .35. Original model with three factor structure (viz., faith, dependency and predictability) were examined through CFA. This three-factor structure showed a good model fit i.e., $X^{2}=229.61(\mathrm{df}=110, \mathrm{p}<.001), \mathrm{X}^{2} / 2=2.08, \mathrm{CFI}=.91, \mathrm{GFI}=.90$, and RMSEA $=.06$. The final model comprised of original three-factor structure and all items were retained (faith having 7 items, dependency with 5 items and predictability with five items subscale). The factor loadings of each item on scale and its subscales ranged from .35 to .80 . SPSS.

To determine the Cronbach's alpha value of Urdu translated scale, reliability analysis was run on

Table 3. Descriptive and Alpha Values of Trust in Close Relationship Scale $(N=250)$

\begin{tabular}{lllll}
\hline Variable & $K$ & Mean & SD & $\alpha$ \\
\hline Dependency & 5 & 18.56 & 3.74 & .75 \\
Faith & 7 & 26.98 & 4.52 & .78 \\
Predictability & 5 & 17.88 & 3.55 & .66 \\
Trust in Close Relationship & 17 & 63.42 & 10.16 & .87 \\
\hline
\end{tabular}

Table 3 indicates the reliability values of TRCS and its subscales. The results show that subscales and total TRCS have promising range of reliability scores (.66 to .87)

Table 4. Inter-correlations between the Sub-scales of Trust in Close Relationship Scale (N=250)

\begin{tabular}{lllll}
\hline Variable & 1 & 2 & 3 & 4 \\
\hline 1. Dependency & - & $.79^{* *}$ & $.81^{* *}$ & $.93^{* *}$ \\
2. Faith & & - & $.86^{* *}$ & $.94^{* *}$ \\
3. Predictability & & & - & $.94^{* *}$ \\
4. Trust in Close Relationship Total & & & & - \\
\hline$* * p<.001$ & & & &
\end{tabular}

Table 4 shows inter-correlations between TCRS and its three subscales. The results indicate that all the sub-scales have strong positive inter-correlations and also strong positive correlations with TCRS total, which complement the reliability of the scale.

\subsection{Phase IV Convergent Validity of Urdu Translated TRCS}

Phase IV of the study aimed to assess the convergent validity of Urdu translated version of TRCS. It was hypothesized that there would be a significant positive relationship between Trust in Close relationship scale (TRCS) and Trust scale (Yamagishi, 1986) for providing the evidence of convergent validity of scale.

\subsubsection{Sample}

A purposive sample of 100 participants (i.e., 50 married couples), living in Lahore city was approached conveniently, among them equal representation of male and female married partners was ensured with age ranging from 23 to 42 years $(M=30.61, S D=4.48)$, having diverse socio-economic backgrounds $(M=2.07, S D=1.19)$. Education of the participants ranged from intermediated to postgraduation $(M=2.83, S D=1.14)$. 


\subsubsection{Instruments}

Trust in Close Relationship Scale (Rempel et al., 1985) and Trust Scale (Yamagishi, 1986) were used in this part of the study. The detail of TCRS has been already discussed.

\subsubsection{Trust Scale (Yamagishi, 1986)}

It is a five items research instrument for measuring the general trust an individual has on others. This scale has two factors including honest factor (one's belief that others are honest) and risk factor (belief that to trust someone is risky). Respondent are required to indicate the degree of agreement or disagreement on a five-point Likert scale ranged from $1=$ strongly disagree to 5 as strongly agree. Honest factor includes item no 1 and 4 (reversed item) whereas risk factor consisted of item no 2, 3, and 5. This scale has good reliability ranged from $\alpha=.70$ to .78 (Yamagishi, \& Yamagishi, 1994) and predictive validity (Yamagishi et al., 1999).

\subsubsection{Procedure}

All scales were distributed individually among sample of 100 married partners (50 men \& 50 women) for establishing the convergent validity of TCRS. Informed consent was obtained from the participants of study and confidentiality of data was ensured. Instructions regarding completion ofthe questionnaires (response formatting) were given, they were also given the right to withdraw their participation at any stage of data collection, but no one quitted. Initially, 120 questionnaires were distributed but 100 were found completed in all dimensions, so the analysis was run on a sample of 100 participants.

\subsubsection{Results}

Table 5. Correlation Matrix of Trust in Close Relationship and its Sub-scales and Trust Scale and its Subscales $(N=250)$

\begin{tabular}{|c|c|c|c|c|c|c|c|}
\hline Variable & 1 & 2 & 3 & 4 & 5 & 6 & 7 \\
\hline 1. Dependency & - & $.68 * *$ & $.54 * *$ & $.85 * *$ & $.61 * *$ & $.54 * *$ & $.56 * *$ \\
\hline 2. Faith & & - & $.66^{* *}$ & $.92 * *$ & $.61 * *$ & $.55 * *$ & $.56 * *$ \\
\hline 3. Predictability & & & - & $.83 * *$ & $.76^{* *}$ & $.82 * *$ & $.86 * *$ \\
\hline 4. Trust in Close Relationship & & & & - & $.75^{* *}$ & $.67 * *$ & $.72 * *$ \\
\hline 5. Honest Factor & & & & & - & $.67 * *$ & $.78 * *$ \\
\hline 6. Risk Factor & & & & & & - & $.91 * *$ \\
\hline 7. Trust Scale & & & & & & & - \\
\hline
\end{tabular}

$* * p<.001$

Pearson's correlation analysis was run to find out the relationship between TCRS, its sub-scales, and Trust scale and its sub-scales and to provide evidence for convergent validity of TCRS. Results indicate that the Urdu translated version of Trust in close relation scale (TCRS) and its subscales have significant positive correlation with the Trust Scale and its subscales and the correlation range between $(r$ $=.54, p<.001$ and $r=.91, p<.001)$. 


\section{Discussion}

Trust is a stronger predictor of martial outcomes like; commitment, satisfaction, strain and continuity and a very important construct in the field of psychology, but unfortunately most of scales of trust had been developed in the West and not a single scale has been developed in the cultural context of Pakistan. The current study was carried out to translate and validate the TCRS for Pakistani married couples. TRCS was translated validated for married couples in the present study, because it has been reported that TRCS has wide application in close interpersonal relationship (Asif \& Saim, 2018; Atta et al., 2013).

The original scale consists of three subscales including Dependability, Predictability and Faith. Confirmatory factor analysis was run to confirm the factor structure of the scale. Results of CFA indicated that scale had good model fit to the data and confirmed three factor structure of the original scale (see Table 2). The results showed similarity with the original work on this scale by Rempel et al. (1985) that three factor structure is best for model fit for this scale. Reliability analysis showed that Urdu Translated TCRS and its subscales were reliable and had compatibility with the original scale (see Table $3 \&$ Table 4). The results indicated excellent convergent validity of TCRS and its sub-scales with the Trust Scale and its sub-scales.

The translation and validation of TCRS will help the researchers in the diverse fields to design studies on married couples in the cultural context of Pakistan. Additionally, as a comprehensive measure based on three factors and 17 items, it will help in measuring the level of trust comprehensively whereas, brief scales do not cover the whole lot e.g., General Trust Scale by Yamagishi (1986) does not measure the dimensions of trust separately.

It will help to measure trust in married people who are unable to read and comprehend English language. So, the findings of current study have wide significance as it will increase the interest of researchers in this area in Pakistan and open new horizons of research in social and positive psychology and provide insight to marital counselors, psychotherapist and psychologists to give awareness to people about the importance of trust in interpersonal relationship and its impact on relationship quality.

In the present study, data were collected from Lahore district that confines the generalizability of the findings of study, so in future, data should be collected from other cities of four provinces of Pakistan to get diverse sample. Convergent validity was assessed in the present study, so in the future studies divergent and concurrent validity is recommended to be assessed.

\section{Conclusion}

On the basis of results of the study, we are in a position to proclaim that Urdu version of TCRS is a valid and reliable scale that can be used for future research that aims to assess mutual trust in close relationships in relevance to other psychological constructs.

\section{References}

Asif, A., \& Saim, S. (2018). Trust and marital satisfaction among single and dual career couples. MedCrave Group LLC. https://medcraveebooks.com/view/Trust-and-Marital-Satisfaction-among$\underline{\text { Single-and-Dual-Career-Couples.pdf }}$

Atta, M., Adil, A., Shujja, S., \& Shakir, S. (2013). Role of trust in marital satisfaction among single and dual-career couples. International Journal of Research Studies in Psychology, 2(4), 5362.doi:10.5861/ijrsp.2013.339 
Brislin, R. W. (1970). Back translation for the cross-cultural research. Journal of Cross Cultural Research, 1(3), 185-216.

Brislin R. W. (1976). Translation, application, and research. New York, NY: John Wiley \& Sons, Inc.

Brislin, R. W. (1976). Comparative research methodology: Cross- cultural studies. International Journal of Psychology, 11(3), 215-229.

Cottrell, C. A., Neuberg, S. L., \& Li, N. P. (2007). What do people desire in others? A socio functional perspective on the importance of different valued characteristics. Journal of Personality and SocialPsychology, 92(2), 208-231. http://dx.doi.org/10.1037/0022-3514.92.2.208

Dobing, B. (1993). Building trust in user-analyst relationships, (Unpublished doctoral dissertation), Carlson School of Management, University of Minnesota.

Fatima, M., \& Ajmal, M. A. (2012). Happy marriage: A qualitative study. Pakistan Journal of Social and Clinical Psychology,10(1), 37-42.

Fletcher, G. J. O., Simpson, J. A., \& Thomas, G. (2000). The measurement of perceived relationship quality components: A confirmatory factor analytic approach. Personality and SocialPsychology Bulletin, 26, 340-354. https://doi.org/10.1177/0146167200265007

Franz, A. M. (2012), "Interpersonal control in dating relationships: how is it affected by trust in one's partner and adult attachment style?". Theses and Dissertations, 509. https://rdw.rowan.edu/etd/509

Gondal, U., Makhdoom, I. F., \& Atta, M. (2018, November). Moderating role of trust between the relationshipof Machiavellianism and marital satisfaction. Paper presented at the 7 th International Conference on Positive Psychology: Developing a Flourishing Community, National Institute of Psychology, Islamabad, Pakistan.

Gottman, J. (1999b). The seven principles that make marriage last. New York: Three Rivers Press.

Gottman, J., Murray, J., Swanson, C., Tyson, R., \& Swanson, K. (2002). The mathematics of marriage: Dynamic nonlinear models. Cambridge, MA: MIT Press.

Gottman, J., \& Levenson, R. W. (2002). A two-factor model for predicting when a couple will divorce: Exploratory analyses using 14-year longitudinal data. Family Process, 41(1), 83-96.

Gottman, J. M. (2011). The science of trust: Emotional attunement for couples. New York, NY: Norton.

Gottman, J. M. (2015). Principia amoris: The new science of love. New York, NY: Routledge.

Gottman, J. M., Driver, J., \& Tabares, A. (2015). Repair during marital conflict in newlyweds: How couples move from attack-defend to collaboration. Journal of Family Psychotherapy, 26(2), 85108. http://dx.doi.org/10.1080/08975353.2015.1038962

Gottman, J. M., \& Silver, N. (2016). The seven principles for making marriage work. New York, NY: Random House

Heller, D. (2000). How to build trust in marriage. Retrieved October 22, 2013, from http://www.aish.com/f/m/48957116.html

Holmes, J. G., \& Rempel, J. K. (1989). Trust in close relationships. In C. Hendrick (Ed.), Close relationships (pp. 187-220). Newbury Park, CA: Sage. 
Holmes J. G., Boon S. D. \& Adams S. (1990). "The relationship trust scale”, unpublished manuscript, University of Waterloo.

Hooman, H. A. (2016). Structural equational modeling with LISREL application. Samt Publication: Tehran.

Karimi, R., Bakhtiyari, M., \& Masjedi Arani, A. (2019). Protective factors of marital stability in long- term marriage globally: a systematic review. Epidemiology and Health, 41. http://dx.doi.org/10.4178/epih.e2019023

Kelley, D. L., \& Burgoon, J. K. (1991). Understanding marital satisfaction and couple type as functions of relational expectations. Human Communication Research, 18(1), 40-69.

Lahno, B. (2004). The three aspects of interpersonal trust. Analyse \& Kritik, 26, 30-47.

Makhdoom, I., F., \& Malik, N. (2019). Role of Trust in Relating Rewards and Marital Satisfaction among Married Individuals in Pakistan. Foundation University Journal of Psychology, 3(1), 80-107. http://dx.doi.org/10.33897/fujp3.14

McAllister, D. J. (1995). Affect and cognition-based trust as foundations for interpersonal cooperation in organizations. The Academy of Management Journal,38(1), 24-59. https://doi.org/10.2307/256727.

McNulty, M. S. Allan, G. M., Todd, D., McFarran. J. B., \& McCracken, R. M. (1981). Isolation from chicken of rotavirus lacking the rotavirus group. Journal of General Virology, 55, 405-413.

Rao. K. R. \& Tariq. S. (2014-2016). Trust, possessiveness and marital relationship in men and women (Abstract Publication). Punjab University, Lahore.

Rempel, J. K., Holmes, J. G. \& Zanna, M. P. (1985). Trust in close relationships. Journal of Personality and Social Psychology, 49, 95-112.http://dx.doi.org/10.1037/0022-3514.49.1.95.

Rotter, J. B. (1980). Interpersonal trust, trustworthiness, and gullibility. American Psychologist, 35(1), 17. http://dx.doi.org/10.1037/0003-066X.35.1.1

Schneider, I. K., Konijn, E. A., Righetti, F., \& Rusbult, C. E. (2011). A healthy dose of trust: The relationship between interpersonal trust and health. Personal Relationships, 18, 668-676. doi:10.1111/j.1475-6811.2010.01338.x

Shapiro, A. F., Gottman, J. M., \& Carrere, S. (2000). The baby and the marriage: identifying the factors that buffer against decline in marital satisfaction after first baby arrives. Journal of Family Psychology, 14(1), 59-70.doi: 10.1037//0893-3200.14.1.59.

Simpson, J. A. (1990). Influence of attachment styles on romantic relationships. Journal of Personality and Social Psychology, 59, 971-980. https://doi.org/10.1037/0022-3514.59.5.971.

Simpson, J. A. (2007a). Foundations of interpersonal trust. In A. W. Kruglanski \& E. T. Higgins (Eds.), Social psychology: Handbook ofbasic principles (2nd ed., pp. 587-607). New York, NY: Guilford Press.

William, C. D., \& Mark, S. (2008). Marital psychological and physical aggression and children's mental and physical health: Direct, mediated, and moderated effects. Journal ofConsulting and Clinical Psychology, 76(1), 138-148.doi:10.1037/0022-006X.76.1.138

Wong, L., Chu, A., \& Chan, C. (2015). Relationship Trust in the Chinese Context (C-RTS). Journal of Business and Economics, 6(11), 1974-1985. doi:10.15341/jbe(2155-7950)/11.06.2015/017 
and Social Psychology, 51, 110-116. http://dx.doi.org/10.1037/0022-3514.51.1.110

Yamagishi, T., Kikuchi, M., \& Kosugi, M. (1999). Trust, gullibility and social intelligence. Asian Journal of Social Psychology, 2, 145-161. doi: 10.1111/1467-839X.00030

Yamagishi, T. \& Yamagishi, M. (1994). Trust and commitment in the United States and Japan. Motivation and Emotion, 18, 129-166. doi: 10.1007/BF02249397 